\title{
Analysis of continuous GPS measurements from southern Victoria Land, Antarctica
}

Michael J. Willis

Byrd Polar Research Center and School of Earth Sciences, Ohio State University, Columbus, OH 43210, USA (willis.146@osu.edu)

\begin{abstract}
Several years of continuous data have been collected at remote bedrock Global Positioning System (GPS) sites in southern Victoria Land, Antarctica. Annual to sub-annual variations are observed in the position time-series. An atmospheric pressure loading (APL) effect is calculated from pressure field anomalies supplied by the European Centre for Medium-Range Weather Forecasts (ECMWF) model loading an elastic Earth model. The predicted APL signal has a moderate correlation with the vertical position time-series at McMurdo, Ross Island (International Global Navigation Satellite System Service (IGS) station MCM4), produced using a global solution. In contrast, a local solution in which MCM4 is the fiducial site generates a vertical time series for a remote site in Victoria Land (Cape Roberts, ROB4) which exhibits a low, inverse correlation with the predicted atmospheric pressure loading signal. If, in the future, known and well modeled geophysical loads can be separated from the time-series, then local hydrological loading, of interest for glaciological and climate applications, can potentially be extracted from the GPS time-series.

Citation: Willis, M. J. (2007), Analysis of continuous GPS measurements from southern Victoria Land, Antarctica, in Antarctica: A Keystone in a Changing World - Online Proceedings of the $10^{\text {th }}$ ISAES, edited by A.K. Cooper and C. R. Raymond et al., USGS Open File Report 2007-1047, Short Research Paper 064, 5 p.; doi:10.3133/of2007-1047.srp064
\end{abstract}

\section{Introduction}

Crustal bedrock motion due to transient elastic deformation of the Earth's crust that occurs in response to surface load variations throughout the year are expected in southern Victoria Land (SVL), Antarctica. These short lived deformations are superimposed upon longer-term, secular changes in the position of the Earth's crust due to viscoelastic Glacial Isostatic Adjustment (GIA) and ongoing tectonic deformation (James and Ivins, 1998; Ivins and James, 2005; Kauffmann et al., 2005; Willis and Wilson, in preparation). The sources of surface load changes include annual accumulation and ablation of ice masses (e.g., snowfall, summer melt, sublimation), ice mass redistribution from ice dynamics and calving processes, ocean tidal loading (OTL) and atmospheric pressure loading.

Between 1999 and 2007 up to thirteen continuously operating Global Positioning System (GPS) sites were operating at any one time on bedrock in SVL. Six of these were installed at remote sites during the TransAntarctic Mountains DEFormation (TAMDEF) project. The continuous sites were deployed by the Ohio State University in collaboration with the US Geological Survey and Land Information New Zealand (LINZ) and were designed to constrain GIA and tectonic deformation while verifying that annual TAMDEF campaign measurements had correctly sampled the vertical motion of the crust (Willis et al., 2006). The TAMDEF network, shown in Figure 1, covers an area $\sim 750 \mathrm{~km}$ in north-south extent and $350 \mathrm{~km}$ from west to east.

This study examines the daily position time-series for the topocentric 'up' component of two sites. The first is the longest running remote site on the coast of the cratonic Antarctic mainland at Cape Roberts $\left(77^{\circ} 02^{\prime}\right.$ S., $163^{\circ} 11^{\prime}$ E.) shown as ROB4 in Figure 1. This remote site, installed on granitic bedrock, is surrounded on three sides by the Ross Sea, the fourth, western side of the peninsula abuts the calving front of the Wilson Piedmont Glacier, which has undergone retreat of $450 \mathrm{~m}$ in the last $\sim 50$ years (Hall and Denton, 2000). Meltwater from the western flank of this glacier flows into lakes in the McMurdo Dry Valleys during most austral summers (Hall and Denton, 2000; Hall et al., 2001; Hall et al., 2002; Hall and Denton, 2005). Local hydrological load changes are expected to affect this site over the test period from 2002 until 2007.

The second tracker, called MCM4 (77 $50^{\prime}$ S., $166^{\circ}$ $40^{\prime}$ E.), is on a low volcanic hill above McMurdo station, the main logistics hub for the US Antarctic Program (MCM4 on Figure 1.) The GPS site is close to the snout of a glacier that covers the Hut Point Peninsula. Meltwater is seen on the surface of this glacier during most summers and there are extensive drainage channels around its edges.

ROB4 data are processed using the doubledifferencing method, fixing carrier-phase ambiguities in the PAGES-V software package (Mader et al., 1995; Eckl et al., 2001; Soler et al., 2006), produced by the United States National Geodetic Survey. Final IGS precise orbits are used and the data are processed in a local reference frame by constraining MCM4 to its ITRF2000 (Altamimi et al., 2002) daily position.

The remote continuous station examined here is equipped with a choke ring antenna and a SCIGN short hemispherical radome. A radome can reduce the apparent magnitude of atmospheric loading, while also providing a tendency to bias tropospheric delay estimates. The amount of water vapor in the troposphere is correlated with the air pressure. As pressure changes the tropospheric delay estimates vary. This could show up in the GPS time-series as height changes, which could be wrongly interpreted as the response to local load changes (Kaniuth and Vetter, 2006). 


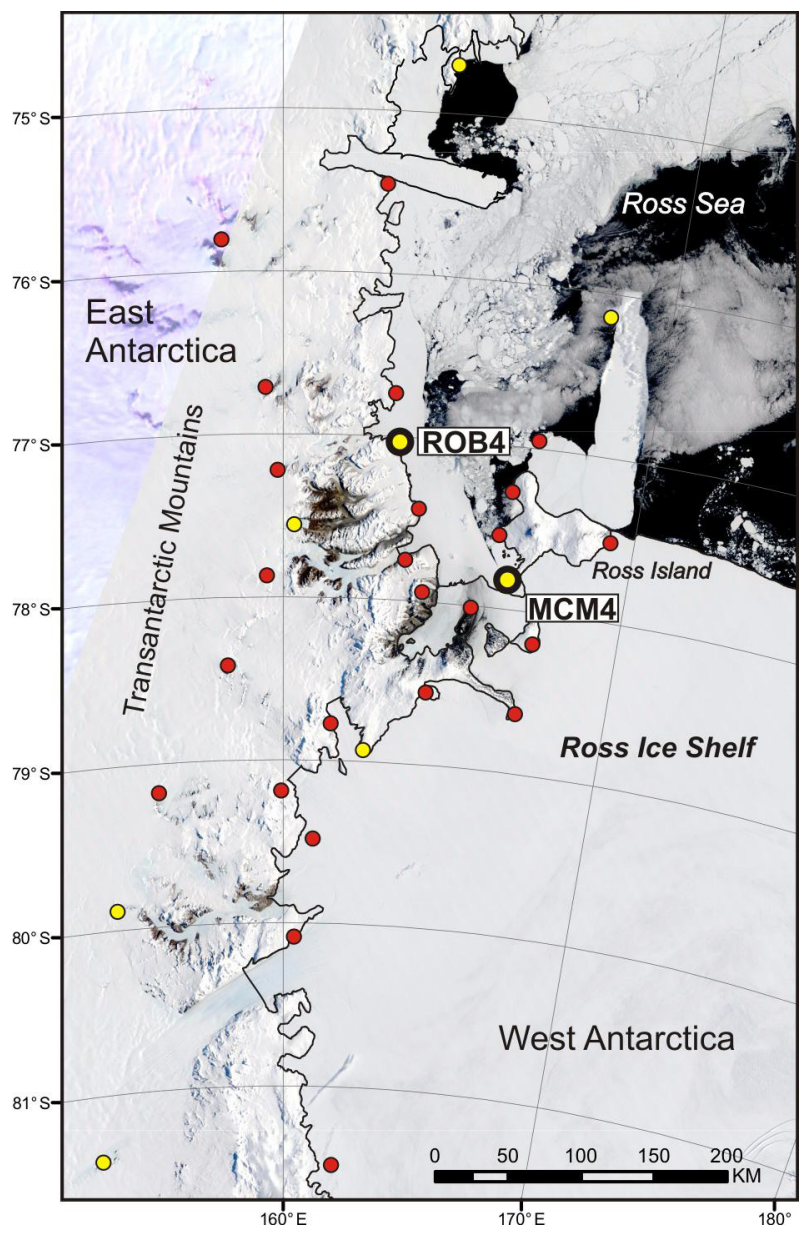

Figure 1. The TAMDEF Network. Red dots - campaign stations. Yellow dots - continuous stations. Yellow dots with heavy border - Stations used in this study. MODIS image from http://visibleearth.nasa.gov.

We use relative antenna phase center variation tables from NGS and the Niell Mapping Function (Niell, 1996) when processing Cape Roberts. The antenna tables and our relatively high elevation cut-off of $15^{\circ}$ should reduce some of the potential height biases. The MCM4 solution is produced with a lower elevation mask of $10^{\circ}$ and utilizes SOPAC orbits and IGS elevation dependant antenna phase center variation tables (Nikolaidis, 2002) .

In order to examine the effects of geophysical loads on MCM4 we use results from a publicly available global solution produced using GAMIT (King and Bock, 1999) by the Scripps Orbit and Permanent Array Center (SOPAC) processing group. Time-series are available at ftp://garner.ucsd.edu/pub/timeseries.

\section{Analysis of vertical motions in GPS time-series}

A normalized set of residuals is produced for each time-series by removing a least-squares calculated linear model. A frequency analysis of the power spectrum of the residual positions through time reveals a dominant annual signal with subdued power in the semi-annual term for ROB4 (Willis et al., submitted J. of Geodesy).
Dragert et al., (2000) note that Ocean Tide Loading (OTL) is important for solutions produced with short duration data and may be especially important when calculating precipitable water vapor estimates on subdaily timescales. They further note that OTL is largely averaged out of solutions produced when using 24-hour duration observations. Two models of OTL are tested using coefficients provided by the website maintained by Bos and Scherneck at http://www.oso.chalmers.se/\%7Eloading/index.html.

The correlation between the average daily OTL produced by the GOT00.2 (Ray, 1999) tide model and the average daily up position time-series at Cape Roberts is 0.02 . The correlation between loading produced by the TPXO.6.2 (Egbert and Erofeeva, 2002) tide model, preferred by King and Padman, (2005) and King et al., (2005) for the Antarctic, and the GPS vertical time series is 0.03 . Similar results are found for MCM4. These very low correlations indicate that the dominant semi-diurnal and diurnal OTL effects are averaged out when using 24hour GPS solutions. Removal of the OTL effect does not significantly reduce the RMS of the 24-hour solution time-series at either ROB4 or MCM4.

Atmospheric Pressure Loading (APL), which is known to cause crustal deformation in Antarctica (Dong et al., 2002), also contains clear daily and sub-daily period signals. These signals average out over 24 -hour periods to leave a clearly seasonal time-series (Tregoning and van Dam, 2005a). The effect of APL has been computed using the center of the figure frame at 6-hour intervals using pressure anomalies from the European Center for Medium-Range Weather Forecasting (ECMWF) model, coupled to an elastic Earth model (van Dam and Herring, 1994; Tregoning and van Dam, 2005a; b). The pressure anomaly range is large at the high latitude under consideration, with an overall peak to peak maximum of over $70 \mathrm{hPa}$ during the study and a maximum daily range of $40 \mathrm{hPa}$. These values are very similar to those experienced at high northern latitudes (Kaniuth and Vetter, 2006).

The atmospheric pressure anomaly fields from the ECMWF were compared to pressure anomaly observations to ascertain the level of agreement and hence the probable quality of the predicted APL signal. Observed pressure anomaly fields were obtained from automatic weather station (AWS) data collected at sites nearby to both ROB4 and MCM4 (ftp://ice.ssec.wisc.edu/pub/aws/10min/rdr).

The correlation between the data from the in-situ measurements and the modeled pressure fields is very high, for MCM4 the correlation and regression coefficients are both greater than 0.98. For Cape Roberts, the nearest AWS is $50 \mathrm{~km}$ farther south, but the correlation and regression coefficients are still both greater than 0.90. These results give confidence that the ECMWF modeled pressure fields are realistic. The correlation between the pressure field anomalies at 
MCM4 and ROB4 are also extremely high (0.98) for both the models and observations, indicating that the pressure field at MCM4 is almost identical to that at Cape Roberts.

McMurdo Station Up and Computed APL

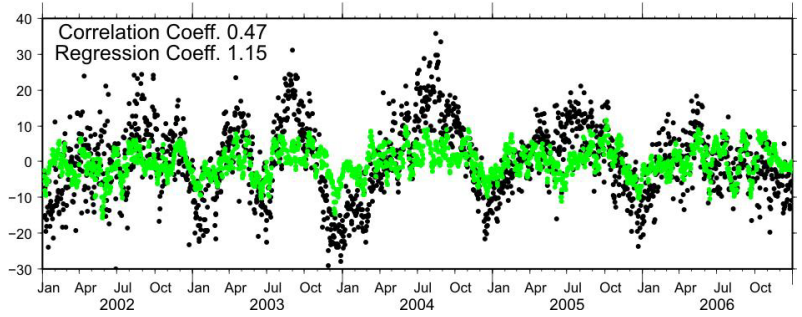

Figure 2. McMurdo Station (MCM4) Up residual (black) plotted with local atmospheric pressure load effect (green) computed from ECMWF pressure fields. MCM4 residuals were calculated from a GAMIT global solution provided by SOPAC. There is a moderate correlation between the APL effect and the position of the GPS.

Cape Roberts Up and Computed APL

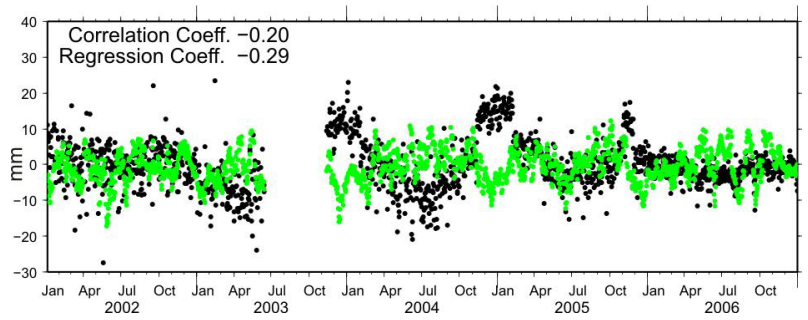

Figure 3. Cape Roberts (ROB4) Up residual (black) produced with a local network analysis (MCM4 held fixed) compared to the local atmospheric pressure load effect (green) computed from ECMWF pressure fields. The gap in the time-series in mid-2003 is due to a large snowdrift covering the solar panels at the site. Offsets in the time-series around January 2004 and November 2005 have no clear explanation but occur at a time of rapidly varying TAMDEF network geometry.
The correlation between the average daily APL effect at MCM4 and the detrended daily "up" position (Figure 2 ) is moderate at 0.47 with about $12 \%$ of the variance in the "up" explained by the APL effect. Low pressure weather systems, prevalent in the austral winter, cause the apparent position of the station to rise. High pressure systems in the summer cause the apparent position of the station to fall. Application of a correction based upon the APL effect at McMurdo reduces the RMS of the timeseries from $10.3 \mathrm{~mm} / \mathrm{yr}$ to $9.1 \mathrm{~mm} / \mathrm{yr}$ for the time period considered. The remaining variation may be related to local hydrological changes, the presence of an uncalibrated radome for which there are no phase center variation corrections and incomplete modeling of the troposphere.

The average daily effect of pressure loading is plotted with the Cape Roberts time-series in Figure 3. The correlation coefficient is much lower than that observed at McMurdo and indicates the pressure loading is the inverse of the apparent residual site position. This is expected since the position of Cape Roberts is tied to the position of MCM4 in our relative processing scheme. As the pressure fields at Cape Roberts and McMurdo are extremely similar, any APL induced motion that occurs at McMurdo will also occur at Cape Roberts. However, McMurdo is tightly constrained in our processing to a linear motion, so the opposite sense of any differential motion that occurs at McMurdo will be transferred into the position time-series of Cape Roberts. For example, during low atmospheric pressure both sites will rise. However, the apparent "up" motion of MCM4 will be transferred as an apparent "down" motion to ROB4, where it will largely cancel out any real upward motion being caused by APL. Residual motion at ROB4 will be the result of local hydrological changes, an equipment configuration differing from McMurdo, a different crustal response to APL due to different local crustal properties compared to McMurdo and poorly modeled troposphere.

Table 1 RMS of selected global GPS sites, from SOPAC Processing

\begin{tabular}{|l|c|c|c|l|l|l|l|c|}
\hline Name & Lat. & Long. & Up RMS (mm) & Name & Lat. & Long. & Up RMS (mm) \\
\hline $\begin{array}{l}\text { MCM4, } \\
\text { Antarctica }\end{array}$ & -77.38 & 166.67 & 11.1 & $\begin{array}{l}\text { HRAO, } \\
\text { South Africa }\end{array}$ & -25.89 & 27.69 & 9.3 \\
\hline $\begin{array}{l}\text { ROB4, } \\
\text { Antarctica* }\end{array}$ & -77.03 & 163.19 & 7.6 & $\begin{array}{l}\text { MALI, } \\
\text { Kenya }\end{array}$ & -3.00 & 40.19 & 12.9 \\
\hline $\begin{array}{l}\text { DAV1, } \\
\text { Antarctica }\end{array}$ & -68.58 & 77.97 & 8.1 & $\begin{array}{l}\text { MAS1, } \\
\text { Gran Canaria }\end{array}$ & 27.76 & -15.63 & 9.4 \\
\hline $\begin{array}{l}\text { CAS1, } \\
\text { Antarctica }\end{array}$ & -66.28 & 110.52 & 6.9 & $\begin{array}{l}\text { GRAZ, } \\
\text { Austria }\end{array}$ & 47.07 & 15.49 & 6.7 \\
\hline $\begin{array}{l}\text { RIOG, } \\
\text { Argentina }\end{array}$ & -53.79 & -67.75 & 9.8 & $\begin{array}{l}\text { DRAO, } \\
\text { Canada }\end{array}$ & 49.32 & -119.63 & 7.9 \\
\hline $\begin{array}{l}\text { HOB2, } \\
\text { Australia }\end{array}$ & -42.80 & 147.44 & 8.9 & $\begin{array}{l}\text { IRKT, } \\
\text { Russia }\end{array}$ & 52.22 & 104.32 & 8.9 \\
\hline
\end{tabular}

*ROB4 from this study. 


\section{Discussion}

Continuous GPS data of sufficient duration to examine various geophysical loads over annual and semiannual timescales has been collected at remote sites around southern Victoria Land. Ocean tidal loading at diurnal and semi-diurnal periods is effectively averaged out of the daily solutions. The modeled local atmospheric pressure loading effect is moderately well correlated with the observations at McMurdo. The correlation coefficients show that atmospheric loading explains less than $20 \%$ of the variance at McMurdo and much less at Cape Roberts. The question therefore remains as to what causes the short term variation in the up position through time for these sites.

The time-series for MCM4 is in phase with the predicted atmospheric pressure loading effect, but is out of phase with other expected geophysical loads. MCM4 apparently rises in mid-winter and falls in mid-summer. In general, mass accumulation on the Antarctic continent occurs as snowfall during the austral winter (Bromwich, 1988; Cullather et al., 1998; Bromwich et al., 2004; Oshima and Yamazaki, 2006; Llubes et al., 2007), which should cause the crust to sink. Around the study area, however, snowfall does not have strong seasonal variability (Monaghan et al., 2005), reducing the seasonal impact. Conversely the atmospheric radiation budget and the amount of ablation on local glaciers is very seasonal. During the warmer temperatures and clear skies of the summer months large amounts of melt are often observed on the glacier adjacent to the MCM4 GPS site (within $50 \mathrm{~m}$ of the tracker). It is likely that this mass loss and redistribution contributes to the motion of the GPS site considering its proximity to the glacier and the very thin, responsive nature of the crust in this part of southern Victoria Land (Bannister et al., 2003; Lawrence et al., 2006).

Bevis et al. (2004) observe a somewhat analogous situation in a similar geological setting in southern Chile. In their study a $1 \mathrm{~km}^{3}$ change in the volume of a lake, $20 \mathrm{~km}$ from their GPS site results in a $7.3 \mathrm{~mm}$ deflection in the vertical. Their elastic model suggests the bedrock beneath the lake would deflect by $40 \mathrm{~mm}$ per cubic kilometer of water change. It is unlikely that the local glacier at McMurdo is fluctuating in volume at a cubic kilometer level, but it is highly likely that sublimation and melting on the glacier contributes to the variation of the GPS position at MCM4. A further complication at the site is the presence of a clear acrylic radome that promotes heavy condensation during the summer months. The presence of this layer of water so close to the antenna element should promote an apparent downward shift in the site during warmer periods. That the observed motions are contrary to the expected motions suggests there are problems with the tropospheric models used during processing, possibly accentuated by the "polar hole" in GPS orbital coverage at this high latitude. A further suggestion is that the scarcity of Southern Hemisphere
GPS sites can influence the resolution of satellite orbit parameters. Of the 130 sites that contribute to the IGS realization of the ITRF2005 reference frame, only 35 are at mid- to high latitudes in the southern hemisphere, compared to 75 at mid- to high latitudes in the northern hemisphere (http://igscb.jpl.nasa.gov). Several other IGS stations in Antarctica demonstrate seasonal motions that are the opposite sense of that expected from hydrological loading and seasonal ice melt (see http://wwwgpsg.mit.edu/ tah/MIT_IGS_AAC/index2.html).

The residual motions of ROB4 are more in phase with expected local hydrological load changes. The effect of removing atmospheric pressure loading from the site is negligible. ROB4 has a lower RMS in the vertical than MCM4 (Table 1) which is probably partially a consequence of the short baselines used in the PAGES processing compared to the SOPAC global solution. The prominent jumps at Cape Roberts around January 2004 and November 2005 are problematic and have no clear explanation. They seem to be related to the rapidly changing TAMDEF network geometry that occurred at these times. The jumps are not as prominent when the data are processed using the BERNESE 4.2 software package (Willis et al., submitted J. of Geodesy).

The competing processes of local hydrological load changes and atmospheric pressure loading combine to provide a complex behavior of GPS sites in this region of Antarctica. Further modeling work and examination of local geophysical loading effects is on-going.

\section{Summary}

Continuous GPS observations have been made in southern Victoria Land, Antarctica. The residual vertical time-series is insensitive to ocean loading as 24-hour data sets are used at both an IGS tracking site (MCM4) and a remote, continuously operating site (ROB4). An atmospheric pressure loading effect (APL) is provided using the European Center for Medium Range Weather Forecasting (ECMWF) model coupled to a simple elastic Earth model. GPS vertical site position from a global solution is moderately correlated with APL for the McMurdo Station site. APL is poorly correlated with the vertical position of the remote site at Cape Roberts generated using a local solution. The residual motion of MCM4 after the predicted APL effect has been removed, is out of phase with expected local hydrological loading. This suggests that the troposphere is being poorly modeled or that there are inaccuracies in the GPS satellite orbits at high southern latitudes. The motion of Cape Roberts is out of phase with expected atmospheric loading but in phase with expected hydrological changes. 
Acknowledgements: This is part of $\mathrm{PhD}$ work by the author, supported by Terry Wilson, PI of the TAMDEF project, through NSF Award ANT0125624. Invaluable field crews were provided by the Byrd Polar Research Center of the Ohio State University, the US Geological Survey, Land Information New Zealand, Geosciences Australia and UNAVCO. APL time-series where kindly provided by Tonie van Dam, of the University of Luxembourg. Automatic Weather Station data provided by the University of Wisconsin Antarctic Meteorological Research Center. The clarity of the paper was much improved with reviews from Stephane Mazzotti, Mirko Scheinert, Thomas James and an anonymous reviewer.

\section{References}

Altamimi, Z., P. Sillard, and C. Boucher (2002), ITRF2000: A new release of the International Terrestrial Reference Frame for Earth science applications, J. Geophys. Res., 107 (B10)(2214).

Bannister, S., J. Yu, B. Leitner, and B. L. N. Kennet (2003), Variations in crustal structure across the transition from West to East Antarctica, Southern Victoria Land., Geophysical Journal International, 155, 870884.

Bevis, M. G., E. Kendrick, A. Cser, and R. Smalley Jr. (2004), Geodetic measurement of the local elastic response to the changing mass of water in Lago Laja, Chile, Phys. Earth Planet. Inter., 141, 71-78.

Bromwich, D. H. (1988), Snowfall in high southern latitudes, Reviews of Geophysics, 26, 149-168.

Bromwich, D. H., Z. Guo, L.-S. Bai, and Q.-S. Chen (2004), Modeled Antarctic Precipitation. Part I: Spatial and Temporal Variability, J. Climate, 17, 427-447.

Cullather, R. I., D. H. Bromwich, and M. L. Van Woert (1998), Spatial and temporal variability of Antarctic precipitation from Atmospheric methods, J. Climate, 11(334-368).

Dong, D., P. Fang, Y. Bock, M. K. Cheng, and S. Miyazaki (2002), Anatomy of apparent seasonal variations from GPS-derived site position time-series, J. Geophys. Res., 107(B4).

Dragert, H., T. S. James, and A. Lambert (2000), Ocean Loading Corrections for Continuous GPS: A Case Study at the Canadian Coastal Site Holberg, Geophys. Res. Lett., 27(14), 2045-2048.

Eckl, M. C., R. A. Snay, T. Soler, M. W. Cline, and G. L. Mader (2001), Accuracy of GPS-derived relative positions as a function of interstation distance and observation-session duration, J. Geodesy, 75, 633-640.

Egbert, G. D., and S. Y. Erofeeva (2002), Efficient Inverse Modeling of Barotropic Ocean Tides, J. Atmos. Oceanic Technol., 19(2), 183-204.

Hall, B. L., and G. H. Denton (2000), Extent and chronology of the Ross Sea ice sheet and the Wilson Piedmont Glacier along the Scott Coast at and since the last glacial maximum, Geog. Ann., 82(2-3), 337-363.

Hall, B. L., G. H. Denton, and B. Overturf (2001), Glacial Lake Wright, a high-level Antarctic lake during the LGM and early Holocene, Antarctic Science, 13(1), 53-60.

Hall, B. L., G. H. Denton, B. Overturf, and C. H. Hendy (2002), Glacial Lake Victoria, a high-level Antarctic lake inferred from lacustrine deposits in Victoria Valley, J. Quat. Sci., 17(7), 697-706.

Hall, B. L., and G. H. Denton (2005), Surficial geology and geomorphology of eastern and central Wright Valley, Antarctica, Geomorph., 64(1-2), 25-65.

Ivins, E. R., and T. S. James (2005), Antarctic glacial isostatic adjustment: a new assessment, Antarctic Science, 17(4), 541-553.

James, T. S., and E. R. Ivins (1998), Predictions of Antarctic crustal motions driven by present-day ice sheet evolution and by isostatic memory of the Last Glacial Maximum., J. Geophys. Res., 103(B3), 4993-5017.
Kaniuth, K., and S. Vetter (2006), Estimating atmospheric pressure loading regression coefficients from GPS observations, GPS Sol., 10, 126-134.

Kauffmann, G., P. Wu, and E. R. Ivins (2005), Lateral viscosity variations beneath Antarctica and their implications on regional rebound motions and seismotectonics., J. Geodyn., 39(2005), 165-181.

King, M. A., and L. Padman (2005), Accuracy assessment of ocean tide models around Antarctica, Geophys. Res. Lett., 23.

King, M. A., N. T. Penna, and P. J. Clarke (2005), Validation of Ocean Tide Models Around Antarctica using Onshore GPS and Gravity Data, J. Geophys. Res., 110(B08401).

King, R. W., and Y. Bock (1999), Documentation for the GAMIT GPS analysis software, Mass. Inst. of Technol., Cambridge Mass.

Lawrence, J. F., D. A. Wiens, A. A. Nyblade, S. Anandakrishnan, P. J. Shore, and D. Voigt (2006), Crust and upper mantle structure of the Transantarctic Mountains and surrounding regions from receiver functions, surface waves, and gravity: Implications for uplift models, G3 - Geochemistry, Geophysics, Geosystems, 7(10).

Llubes, M., J.-M. Lemoine, and F. Remy (2007), Antarctica seasonal mass variations detected by GRACE, Earth and Planetary Science Letters, 260, 127-136.

Mader, G. L., M. S. Schenewerk, J. R. Ray, W. G. Kass, P. R. Spofford, R. L. Dulaney, and D. G. Pursell (1995), GPS orbit and earth orientation parameter production at NOAA for the International GPS Service for Geodynamics for 1994, in International GPS Service for Geodynamics, 1994 Annual Report, edited, pp. 197-212, Jet Propulsion Laboratory, Pasadena, California.

Monaghan, A. J., D. H. Bromwich, J. G. Powers, and K. W. Manning (2005), The Climate of the McMurdo, Antarctica, Region as Represented by One Year of Forecasts from the Antarctic Mesoscale Prediction System, J. Climate, 18, 1174-1189.

Niell, A. E. (1996), Global Mapping Functions for the Atmosphere Delay at Radio Wavelength., J. Geophys. Res., 101(B2), 3227-3246.

Nikolaidis, R. M. (2002), Observation of Geodetic and Seismic Deformation with the Global Positioning System, Ph.D thesis, 265 pp, University of California at San Diego, San Diego.

Oshima, K., and K. Yamazaki (2006), Difference in seasonal variation of net precipitation between the Arctic and Antarctic regions, Geophys. Res. Lett., 33(L18501).

Ray, R. D. (1999), A Global Ocean Tide Model From TOPEX/POSEIDON Altimetry: GOT99.2, NASA Technical Memorandum, 209478.

Soler, T., P. Michalak, N. D. Weston, R. A. Snay, and R. H. Foote (2006), Accuracy of OPUS solutions for 1- to 4-h observing sessions, GPS Sol., 10, 45-55.

Tregoning, P., and T. van Dam (2005a), Atmospheric pressure loading corrections applied to GPS data at the observation level, Geophys. Res. Lett., 32(L223010).

Tregoning, P., and T. van Dam (2005b), Effects of atmospheric pressure loading and seven-parameter transformations on estimates of geocenter motion and station heights from space geodetic observations., J. Geophys. Res., 10(B03408).

van Dam, T. M., and T. A. Herring (1994), Detection of atmospheric pressure loading using very long baseline interferometry measurements, J. Geophys. Res., 99(B3), 4505-4518.

Willis, M. J., T. J. Wilson, and T. S. James (2006), Bedrock Motions From a Decade of GPS Measurements in Southern Victoria Land, Antarctica., Eos Trans. AGU, 87(52).

Willis, M. J., and T. J. Wilson (in preparation), Neotectonics in the Antarctic Interior. 